\title{
Mode of Metabolism of 1-Tetradecene by Candida Yeasts and Citrates Production ${ }^{\dagger}$
}

\author{
Masato Terasawa and Joji TaKahashi \\ Institute of Applied Biochemistry, University of Tsukuba, \\ Ibaraki 305, Japan
}

Received March 12, 1981

\begin{abstract}
Metabolic pathways for the oxidation of 1-tetradecene by Candida lipolytica were investigated and compared with those for Candida tropicalis in order to elucidate the difference in the productivity of citrates reported in the previous paper. No difference was found in the pathways for the initial stage of oxidation of 1-tetradecene between the two strains, indicating that the difference in the productivity of citrates is not attributable to the metabolic pathways. The metabolic rate of 1 tetradecene with $C$. lipolytica was found to be much lower than that with $C$. tropicalis. The production of citrates was much enhanced in the presence of surfactants which were known to be stimulative for microbial metabolism of hydrocarbons and $11 \sim 15 \mathrm{~g} /$ liters was attained on the 6 th day of cultivation.
\end{abstract}

Liquid $\alpha$-olefins produced by thermal cracking of paraffin wax, as described in the previous paper, ${ }^{1)}$ is expected to be a promising novel feed stock for the microbial production of organic acids.

We have investigated the production of citric acids (citric and isocitric acid) from 1tetradecene by using two Candida yeasts and have found, as reported in the previous paper, ${ }^{1)}$ that Candida tropicalis IFO 0589 grows well on 1-tetradecene and accumulates a large amount of citric acids, while Candida lipolytica IFO 0746 also grows well on 1-tetradecene but hardly accumulates citric acids at all. These results suggest that the metabolic pathway or the mode of metabolism of 1-tetradecene by $C$. lipolytica is different from those by $C$. tropicalis.

In this paper, therefore, the metabolic pathways in the initial stage of oxidation of 1tetradecene by these yeasts have been investigated and the $Q_{02}$ value on 1-tetradecene and its metabolic intermediates, which represents the rate of metabolism of each substrate,

$\uparrow \quad$ Utilization of $\alpha$-Olefins by Yeasts. Part II. For Part I, see ref. 1. A part of this paper was presented at the Annual Meeting of the Society of Fermentation Technology, Japan, Osaka, November, 1980. has also been measured in order to elucidate the difference in the productivity of citric acids between $C$. lipolytica and $C$. tropicalis.

\section{MATERIALS AND METHODS}

Microorganisms. Candida tropicalis IFO 0589 and Candida lipolytica IFO 0746 capable of utilizing liquid paraffins and $\alpha$-olefins for growth were used throughout the experiments.

Media. A culture medium (medium A) for harvesting cells or cultivating seeds contained $\mathrm{NH}_{4} \mathrm{Cl}, 6.5 \mathrm{~g}$; $\mathrm{Na}_{2} \mathrm{HPO}_{4} \cdot 12 \mathrm{H}_{2} \mathrm{O}, 1.5 \mathrm{~g} ; \mathrm{KH}_{2} \mathrm{PO}_{4}, 3.5 \mathrm{~g} ; \mathrm{MgSO}_{4} \cdot 7 \mathrm{H}_{2} \mathrm{O}$, $0.5 \mathrm{~g} ; \quad \mathrm{FeSO}_{4} \cdot 7 \mathrm{H}_{2} \mathrm{O}, 10 \mathrm{mg} ; \quad \mathrm{MnSO}_{4} \cdot n \mathrm{H}_{2} \mathrm{O}, \quad 0.1 \mathrm{mg} ;$ $\mathrm{ZnSO}_{4} \cdot 7 \mathrm{H}_{2} \mathrm{O}, 0.1 \mathrm{mg}$; $\mathrm{CuSO}_{4} \cdot 5 \mathrm{H}_{2} \mathrm{O}, 5 \mu \mathrm{g}$; biotin, $100 \mu \mathrm{g}$; thiamin- $\mathrm{HCl}, 100 \mu \mathrm{g}$ and yeast extract, $200 \mathrm{mg}$ in $1000 \mathrm{ml}$ of distilled water, and the $\mathrm{pH}$ was adjusted to 7.0. Another medium (medium $\mathrm{B}$ ) for the production of citric acids consisted of $\mathrm{NH}_{4} \mathrm{Cl}, 2 \mathrm{~g} ; \mathrm{KH}_{2} \mathrm{PO}_{4}, 0.5 \mathrm{~g} ; \mathrm{MgSO}_{4} \cdot 7 \mathrm{H}_{2} \mathrm{O}$, $0.5 \mathrm{~g} ; \mathrm{FeSO}_{4} \cdot 7 \mathrm{H}_{2} \mathrm{O}, 10 \mathrm{mg} ; \mathrm{MnSO}_{4} \cdot n \mathrm{H}_{2} \mathrm{O}, \quad 0.1 \mathrm{mg}$; $\mathrm{ZnSO}_{4} \cdot 7 \mathrm{H}_{2} \mathrm{O}, 0.1 \mathrm{mg} ; \mathrm{CuSO}_{4} \cdot 5 \mathrm{H}_{2} \mathrm{O}, 5 \mu \mathrm{g}$; biotin, $100 \mu \mathrm{g}$ and thiamin- $\mathrm{HCl}, 100 \mu \mathrm{g}$ in $1000 \mathrm{ml}$ of distilled water. To the above media, an appropriate amount of carbon source was added for supporting cellular growth or citric acids production.

Cultivation. For producing cells or cultivating seeds, $50 \mathrm{ml}$ of medium A supplemented with $2 \mathrm{ml}$ of 1-tetradecene in a $500 \mathrm{ml}$ shake flask were inoculated with five loopfuls of $3 \sim 4$ day old cells grown on 1-tetradecene-agar slant and incubated at $30^{\circ} \mathrm{C}$ for 3 days on a reciprocal 
shaker (125 oscills./min, $70 \mathrm{~mm}$ stroke). In the course of cellular growth, $0.5 \mathrm{~g}$ of sterilized calcium carbonate were added to keep the $\mathrm{pH}$ of culture system around 6.0 .

For testing the production of citric acids from various carbon sources such as 1-tetradecene and its metabolic intermediates, $2 \mathrm{ml}$ of medium B supplemented with $100 \mathrm{mg}$ of carbon source in a large test tube $(21 \times 200 \mathrm{~mm})$ were inoculated with $0.1 \mathrm{ml}$ of seed culture and incubated at $30^{\circ} \mathrm{C}$ for 6 days with continuous shaking. In this case, $0.06 \mathrm{~g}$ of sterilized calcium carbonate were added to the culture system at the 24 th $\mathrm{hr}$ of cultivation.

To examine the effect of surfactants on the production of citric acids, cultivations were carried out in a $500 \mathrm{ml}$ shake flask containing $50 \mathrm{ml}$ of medium B supplemented with $3 \mathrm{ml}$ of 1 -tetradecene and $25 \mathrm{mg}$ of surfactant for 6 days under the same cultural conditions as above.

Determination of citrates. Fermentation broth was adjusted to $\mathrm{pH} 2$ with $4 \mathrm{~N}-\mathrm{HCl}$ and centrifuged at $5000 \times \mathrm{g}$ for $10 \mathrm{~min}$. Citric acid in the supernatant obtained was determined by a spectrophotometrical methods using pentabromacetone, ${ }^{2)}$ and the amount of total citric acids (citric + isocitric acid) was determined after the method of Tabuchi et al. ${ }^{3 \text { ' }}$ which modified Saffran's method.

Accumulation of metabolic intermediates of 1-tetradecene. Cells were harvested at the exponential growth phase and washed once with $1 / 15 \mathrm{M}$ phosphate buffer $(\mathrm{pH}$ 7.0 ). The washed cells were resuspended in $1 / 15 \mathrm{M}$ buffer to make a reaction mixture which was composed of $20 \mathrm{ml}$ of the cell suspension (containing $5 \mathrm{~g}$ of resting cells) and $1 \mathrm{~g}$ of substrate and incubated at $30^{\circ} \mathrm{C}$ for 4 days with continuous shaking.

Isolation and identification of metabolic intermediates. The mixture of oxidation products shown in Fig. 1 was methylated and applied to a silicic acid (Wakogel C-200) column $(19 \times 300 \mathrm{~mm})$. The column was eluted with $300 \mathrm{ml}$ of a hexane-ether $(80: 20)$ mixture to recover alcoholic and acidic oxidation products. This fraction (tentatively designated as fraction A) was analyzed by means of gas-liquid chromatography and mass spectrometry for the identification of products.

A Shimadzu GC-4C equipped with a flame ionization detector was used for gas-liquid chromatography, and a Hitachi RMU-6E was employed in the mass spectrometric analysis.

The gas-liquid chromatography was performed on a stainless-steel column $(3 \mathrm{~mm} \times 2 \mathrm{~m})$ packed with $60 / 80$ mesh Chromosorb W-AW coated with $30 \%$ Silicone SE30. The detector and injection port were maintained at $270^{\circ} \mathrm{C}$. The column temperature was programmed at $2^{\circ} \mathrm{C} / \mathrm{min}$ from 160 to $230^{\circ} \mathrm{C}$. The carrier gas was $\mathrm{N}_{2}$ with a flow rate of $20 \mathrm{ml} / \mathrm{min}$. The mass spectra were taken by using $70 \mathrm{eV}$ ionizing energy.

Rate of oxygen uptake. The rates of oxygen uptake on various substrates were determined by using a Warburg constant volume manometer at $30^{\circ} \mathrm{C}$. The starved cells employed were prepared by incubating 1-tetradecenegrown cells, which were harvested by the procedure described above, in $1 / 15 \mathrm{~m}$ phosphate buffer at $30^{\circ} \mathrm{C}$ for $6 \mathrm{hr}$ with continuous shaking.

Chemicals. 1-Tetradecene was purchased from Tokyo Kasei Kogyo Co. and $96.7 \%$ grade. The other chemicals used were of the highest grade commercially available.

\section{RESULTS AND DISCUSSION}

\section{Metabolic pathways for the oxidation of 1- tetradecene}

As to the oxidation of $\alpha$-olefins by yeasts, two metabolic pathways have been report-

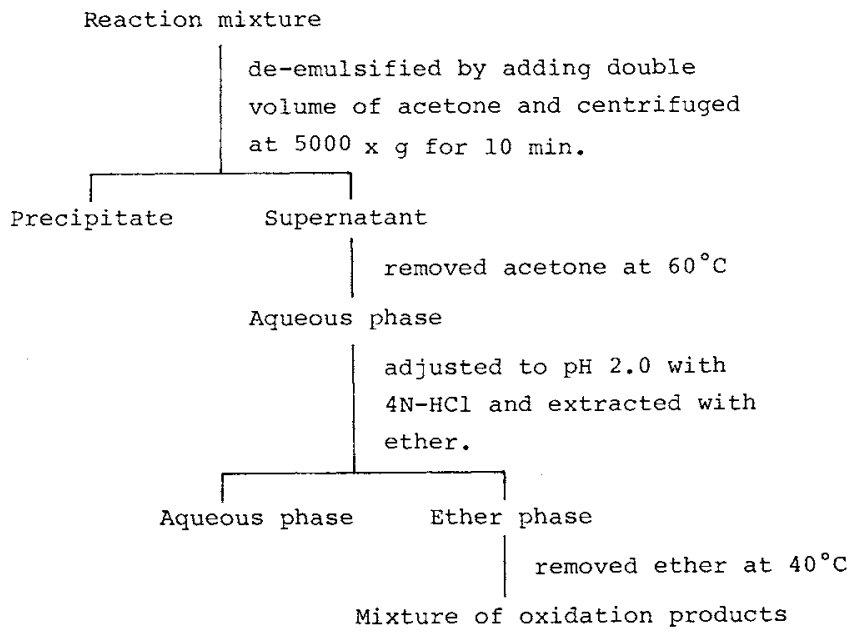

FIG. 1. Procedures for Isolation of Oxidation Products. 
ed. ${ }^{4,5)}$ One (pathway I) begins with the oxidation of unsaturated site into 1,2-epoxide followed by the oxidations to form 1,2-diol and $\alpha$-hydroxycarboxylic acid, which is further decarboxylated into saturated fatty acid. The other (pathway II) begins with the oxidation of saturated site to form primary alcohol, which is further oxidized into unsaturated fatty acid.

Metabolic intermediates of 1-tetradecene accumulated by resting cells of $C$. lipolytica and $C$. tropicalis were firstly examined in order to check the pathways for the oxidation of 1 tetradecene by both strains.

Figure 2 shows the gas-liquid chromatograms of fraction A recovered from the culture filtrates of both strains by the procedure described above. Two products, $\mathrm{P}_{1}$ and $\mathrm{P}_{2}$, as shown in Fig. 2-I, were detected in the fraction from C. lipolytica, while only one product, $\mathrm{P}_{1}$, as shown in Fig. 2-II, was detected in the fraction from $C$. tropicalis. Based on the retention times in gas-liquid chromatography and the mass spectra shown in Fig. 5, $P_{1}$ and $\mathrm{P}_{2}$ were found to be identical with methyl tridecanoate (corresponding to tridecanoic acid as metabolic intermediate) and methyl $\alpha$ -

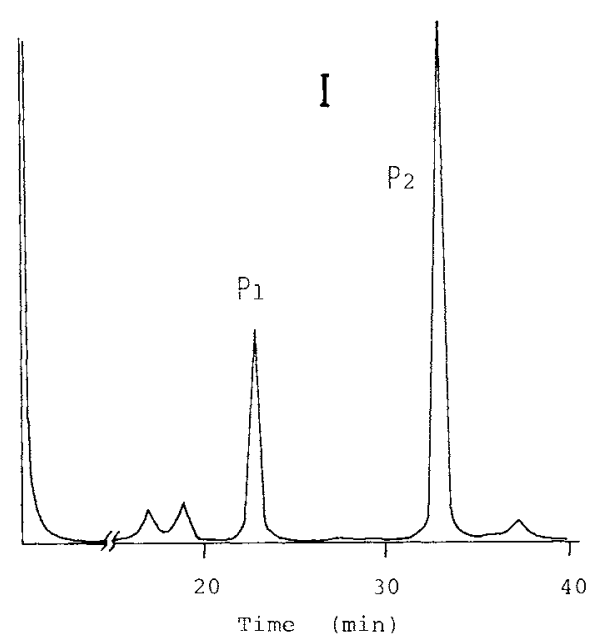

hydroxymyristate (corresponding to $\alpha$-hydroxymyristic acid as metabolic intermediate), respectively. This suggests that both $C$. lipolytica and $C$. tropicalis oxidized 1-tetradecene via pathway I. This suggestion is also supported by the results in Table I showing that

\section{Table I. OXygen Uptake on Metabolic INTERMEDIATES OF I-TETRADECENE}

In the main compartment of a Warburg flask were placed $1.7 \mathrm{ml}$ of phosphate buffer ( $\mathrm{pH} 7.0$ ) containing substrate $3 \%(\mathrm{w} / \mathrm{v})$. The center well of the flask contained $0.2 \mathrm{ml}$ of $20 \%(\mathrm{w} / \mathrm{v}) \mathrm{KOH}$, and the side arm contained $0.5 \mathrm{ml}$ of cell suspension containing $3 \sim 4 \mathrm{mg}$ cells (dry basis).

\begin{tabular}{ccc}
\hline & \multicolumn{1}{c}{$\begin{array}{c}\text { Rate of oxygen uptake } \\
Q_{02}(\mu \mathrm{l} / \mathrm{mg} \cdot \mathrm{hr})\end{array}$} \\
\cline { 2 - 3 } Intermediates & C. tropicalis & C. lipolytica \\
\hline $\begin{array}{c}\text { 1,2-Epoxy - } \\
\text { tetradecane } \\
\alpha \text {-Hydroxy- } \\
\text { myristic acid } \\
\begin{array}{c}\text { Tridecanoic } \\
\text { acid }\end{array}\end{array}$ & 34.0 & 20.7 \\
$\begin{array}{c}\text { Myristoleic } \\
\text { acid }\end{array}$ & 73.9 & 19.7 \\
\hline
\end{tabular}

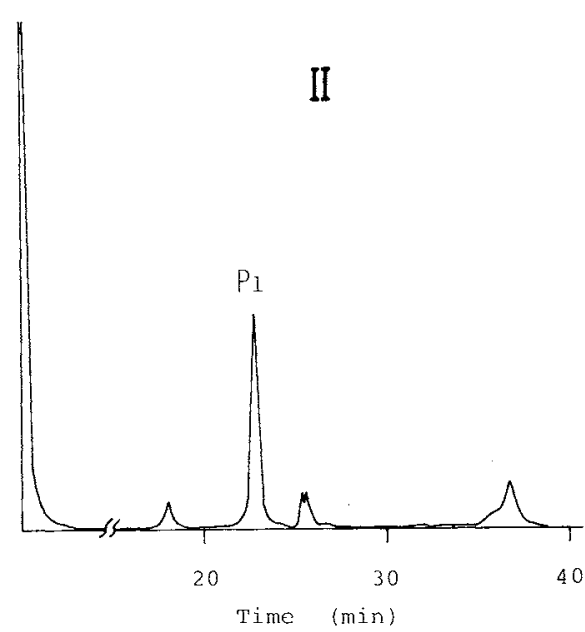

FIG. 2. Gas-liquid Chromatograms of Oxidation Products Produced from 1-Tetradecene.

I, Candida lipolytica; II, Candida tropicalis.

Peaks: $P_{1}$, methyl tridecanoate; $P_{2}$, methyl $\alpha$-hydroxymyristate. Conditions: A strainless-steel column ( $3 \mathrm{~mm} \times 2 \mathrm{~m}$ ) with $30 \%$ Silicone SE-30 on Chromosorb W (AW, 60/80 mesh). Column temperature, $160 \sim 230^{\circ} \mathrm{C}$ (program rate, $2^{\circ} \mathrm{C} / \mathrm{min}$ ). Flow rate $\left(\mathrm{N}_{2}\right), 20 \mathrm{ml} / \mathrm{min}$. 
1,2-epoxytetradecane, $\alpha$-hydroxymyristic and tridecanoic acids belonging to the pathway I are oxidized by both strains at moderate rates. It is notable, however, that myristoleic acid is also oxidized by both strains at fairly high rates, suggesting that the pathway II might also be working for the oxidation of 1-tetradecene, although neither 13-tetradecene-1-ol nor myristoleic acid was detected in the culture filtrates of both strains.

So far as the above results were concerned,
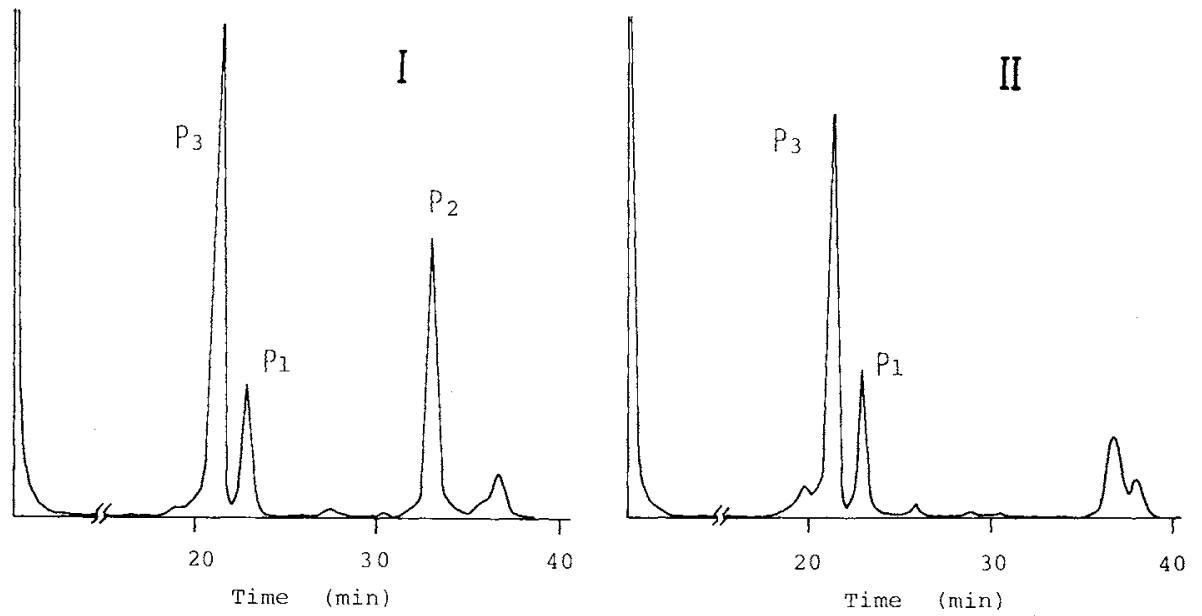

FIG. 3. Gas-liquid Chromatograms of Oxidation Products Produced from 1-Tetradecene in the Presence of Iodoacetamide.

I, Candida lipolytica; $\mathbf{I}$, Candida tropicalis.

Peaks: $P_{1}$, methyl tridecanoate; $P_{2}$, methyl $\alpha$-hydroxymyristate; $P_{3}, 2$-methoxytetradecane. Conditions are the same as those in Fig. 2.
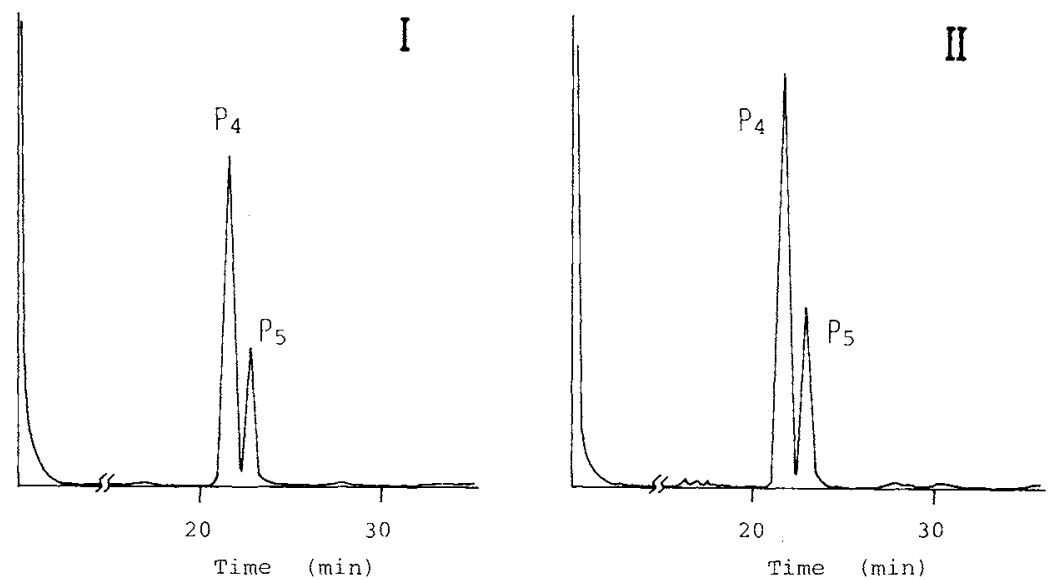

FIG. 4. Gas-liquid Chromatograms of Oxidation Products Produced from 2-Tetradecanol.

I, Candida lipolytica; II, Candida tropicalis.

Peaks: $\mathrm{P}_{4}, 2$-tetradecanone; $\mathrm{P}_{5}$, methyl tridecanoate. Conditions are the same as those in Fig. 2. 

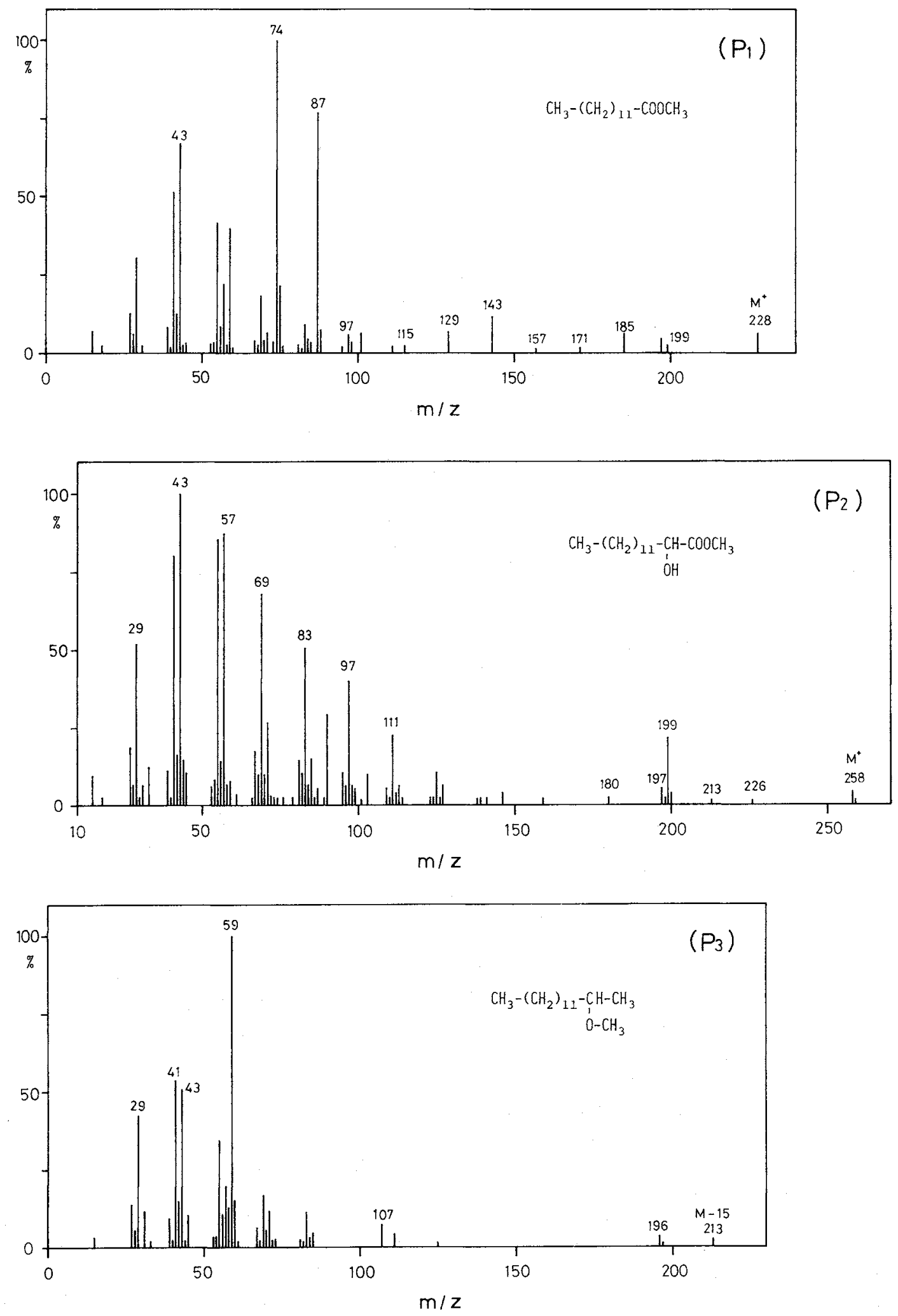


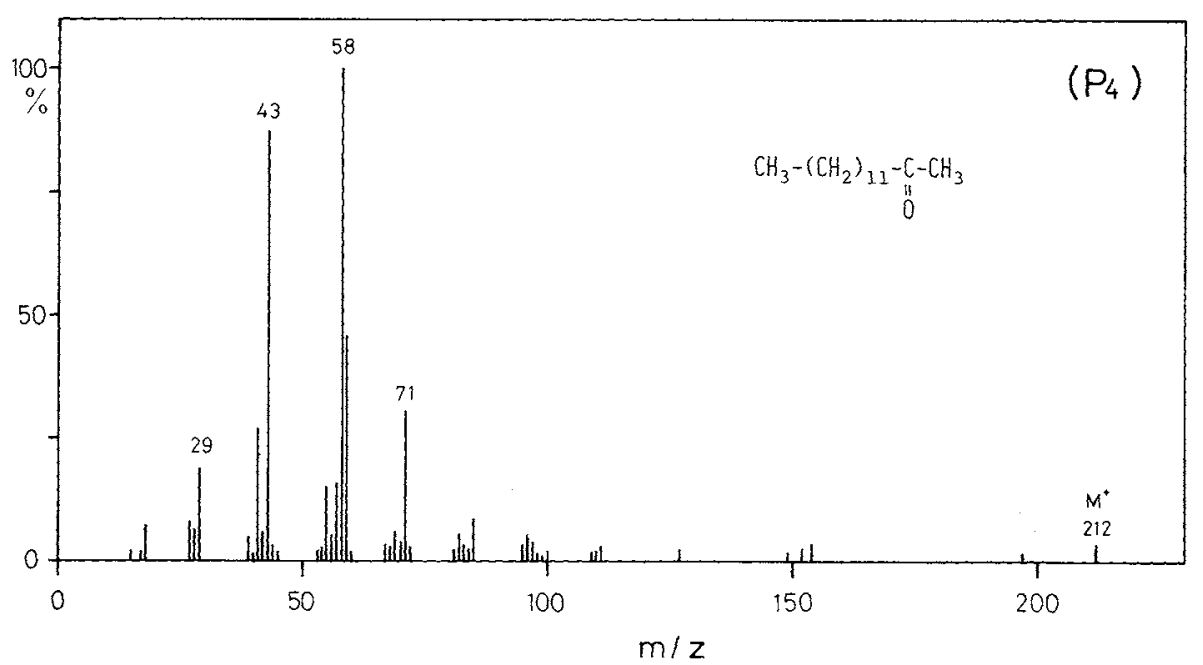

FiG. 5. Mass Spectra of Products $P_{1}, P_{2}, P_{3}$ and $P_{4}$.

lonizing energy was $70 \mathrm{eV}$ and accelerating voltage was $1800 \mathrm{~V}$.

Table II. Citrates Production and Oxygen Uptake on 1-Tetradecene and Its Metabolic InTERmediates

\begin{tabular}{|c|c|c|c|c|}
\hline \multirow[b]{2}{*}{ Substrates } & \multicolumn{2}{|c|}{ C. tropicalis } & \multicolumn{2}{|c|}{ C. lipolytica } \\
\hline & $\begin{array}{c}\text { Total }^{a} \\
\text { citrates } \\
\text { (g/liter) }\end{array}$ & $\begin{array}{c}Q_{02}^{b} \\
(\mu \mathrm{l} / \mathrm{mg} \cdot \mathrm{hr})\end{array}$ & $\begin{array}{l}\text { Total }^{a} \\
\text { citrates } \\
\text { (g/liter) }\end{array}$ & $\underset{(\mu \mathrm{l} / \mathrm{mg} \cdot \mathrm{hr})}{Q_{\mathrm{o} 2}{ }^{b}}$ \\
\hline$n$-Tetradecane & 45.5 & 34.6 & 40.6 & 28.8 \\
\hline 1-Tetradecene & 36.6 & 33.5 & 3.9 & 13.8 \\
\hline Tridecanoic acid & 21.8 & 73.9 & 20.7 & 58.0 \\
\hline 2-Tetradecanol & 50.0 & 49.1 & 40.1 & 42.3 \\
\hline
\end{tabular}

a Cultivations were carried out in large test tubes $(21 \times 200 \mathrm{~mm})$ containing $2 \mathrm{ml}$ of medium $\mathbf{B}$ (described in the text) supplemented with $100 \mathrm{mg}$ of carbon source at $30^{\circ} \mathrm{C}$ for 6 days with continuous shaking.

${ }^{b}$ Experimental conditions were the same as those in Table I.

each other in detail, and one more intermediate, in addition to $\mathrm{P}_{1}$ and $\mathrm{P}_{2}$, was found to be accumulated by both strains by the presence of iodoacetamide, an inhibitor to isocitrate dehydrogenase. ${ }^{6}$ This product, $\mathrm{P}_{3}$, was detected in fraction $A$ as shown in gas-liquid chromatograms in Fig. 3 and was identified with 2-methoxytetradecane (corresponding to 2-tetradecanol as metabolic intermediate) by analyzing mass spectrum shown in Fig. $5-\mathrm{P}_{3}$.

Two oxidation products were further accumulated, when 2-tetradecanol was subjected to the oxidation by resting cells of both strains, and detected in fraction $\mathrm{A}$ as shown by peaks $\mathrm{P}_{4}$ and $\mathrm{P}_{5}$ in gas-liquid chromatograms in Fig.
4. Peak $P_{5}$ was supposed to be identical with methyl tridecanoate (corresponding to tridecanoic acid as an oxidation product), since the retention time of $P_{5}$ in Fig. 4 was the same as that of peak $P_{1}$ in Fig. 2. $P_{4}$ was identified with 2-tetradecanone by analyzing mass spectrum shown in Fig. 5- $\mathrm{P}_{4}$. In addition, as shown in Table II, 2-tetradecanol was oxidized at fairly high rates and utilized by both strains for the production of citrates as well as for the cellular growth.

Above results suggest that a new alternative pathway, in which 1-tetradecene is oxidized via 2-tetradecanol and 2-tetradecanone, may be present in both $C$. lipolytica and $C$. tropi- 
calis, although further enzymatic studies are required to make the presence of this new pathway sure.

On the other hand, the fact that 1-tetradecene was oxidized by both strains in the same alternative way in the presence of such a metabolic inhibitor as iodoacetamide may also support the conclusion that there is no difference, by which the difference in the productivity of citrates is elucidated, in the metabolic pathway for the initial stage of oxidation of 1-tetradecene between C. lipolytica and $C$. tropicalis.

Citrates production and oxygen uptake on 1tetradecene and its metabolic intermediates

After coming to the above conclusion, we next examined the productivity of citrates to see whether it was related to the rate of the metabolism of the substrates, since the $Q_{\mathrm{o} 2}$ value of $C$. lipolytica on each of the metabolic intermediates of 1-tetradecene, as shown in Table I, was found to be somewhat lower than that of $C$. tropicalis on the same substrate. Table II shows the amount of citrates produced and the rate of oxygen uptake on $n$ tetradecane, 1-tetradecene, tridecanoic acid and 2-tetradecanol. The results in this table indicate that the ratio of the productivity of citrates by $C$. lipolytica to that by $C$. tropicalis on each substrate is roughly equal to the ratio of the $Q_{\mathrm{o} 2}$ value of $C$. lipolytica to that of $C$. tropicalis on that substrate. Above all, it is notable that the $Q_{\mathrm{o} 2}$ value of $C$. $l i$ polytica on 1-tetradecene is much lower than that of $C$. tropicalis on 1-tetradecene and $C$. lipolytica on $n$-tetradecane, and the reason why 1-tetradecene is utilized by C. lipolytica for the growth but not for the production of citrates seems to be closely related to the low $Q_{02}$ value indicating that the rate of metabolism of 1-tetradecene is relatively low.

\section{Effects of surfactants on citrates production}

The above assumption may be confirmed if the production of citrates from 1-tetradecene by $C$. lipolytica is stimulated by increasing the
Table III. Effect of Surfactants on Citrates Production From 1-TetradecENe BY C. lipolytica

Cultivations were carried out in $500 \mathrm{ml}$ shake flasks containing $50 \mathrm{ml}$ of medium $\mathrm{B}$ (described in the text) supplemented with $3 \mathrm{ml}$ of 1-tetradecene and $25 \mathrm{mg}$ of surfactant (or $1 \mathrm{ml}$ of $\mathrm{RL}$ concentrate*) at $30^{\circ} \mathrm{C}$ for 6 days on a reciprocal shaker (125 oscills. $/ \mathrm{min}, 70 \mathrm{~mm}$ stroke).

\begin{tabular}{lc} 
Surfactants & $\begin{array}{c}\text { Total citrates } \\
\text { (g/liter) }\end{array}$ \\
\hline Span 80 & 13.2 \\
Tween 80 & 11.2 \\
Tween 20 & 12.3 \\
RL concentrate* & 14.4 \\
No addition & 2.6 \\
\hline
\end{tabular}

* Culture filtrate of $P$. aeruginosa grown on $n$ tetradecane.

rate of metabolism of the substrate. Therefore, three surfactants, Tween 20, Tween 80 and Span 80, which had been reported to be effective in increasing the rate of microbial metabolism of hydrocarbons, ${ }^{7,8)}$ were tested for the stimulation of citrates production from 1-tetradecene. A concentrate (tentatively designated as RL concentrate) of culture filtrate from Pseudomonas aeruginosa grown on $n$ tetradecane was also tested, since it had been reported that a rhamnolipid contained in the filtrate stimulated the microbial metabolism of hydrocarbons. ${ }^{9,10)}$

The results obtained are shown in Table III. All of the four surfactants tested strongly stimulated the citrates production, and the accumulation of citrates attained to $11 \sim 15$ $\mathrm{g} /$ liter on the 6 th day of cultivation in the presence of one of these surfactants, while only $2 \sim 3 \mathrm{~g} /$ liter of citrates were produced in the absence of surfactants. In Fig. 6, a time course of citrates production from 1-tetradecene by $C$. lipolytica in the presence of $R \mathrm{~L}$ concentrate is compared to that in its absence. In the initial stage of the cultivation, as shown in the figure, 1-tetradecene was consumed more rapidly in the presence of $\mathrm{RL}$ concentrate than in its absence, and the stimulation of the consumption of 1-tetradecene in this phase of growth seemed to have a signifi- 


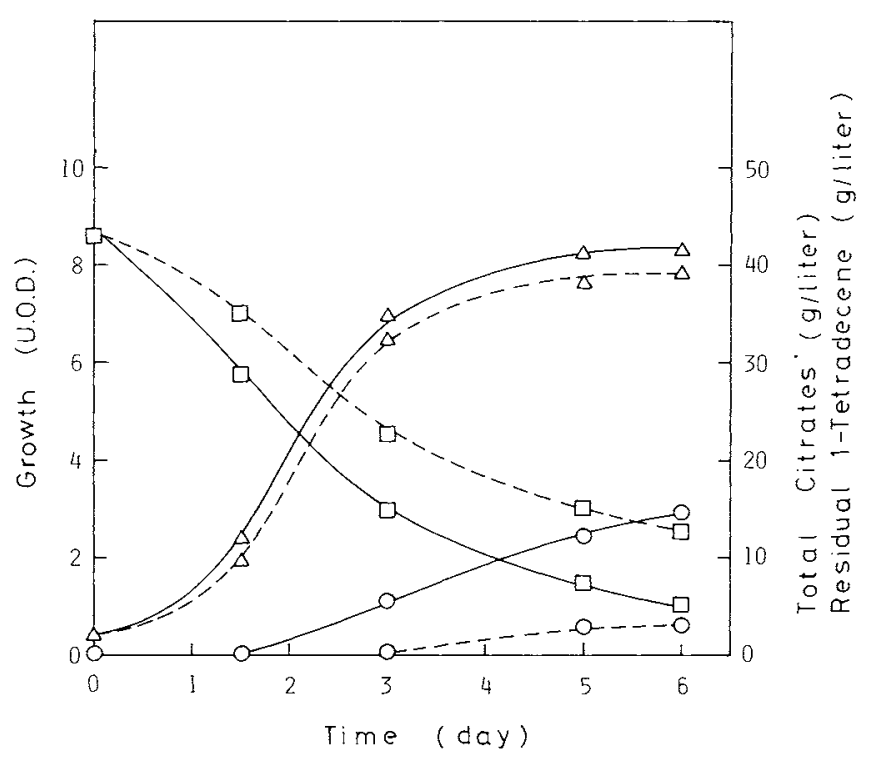

FIG. 6. Effect of RL concentrate* on Citrates Production from 1-Tetradecene by Candida lipolytica.

The cultures were incubated at $30^{\circ} \mathrm{C}$ in $500 \mathrm{ml}$ shake flasks containing $50 \mathrm{ml}$ of medium B (described in the text) supplemented with $3 \mathrm{ml}$ of 1 -tetradecene and $1 \mathrm{ml}$ of $\mathrm{RL}$ concentrate* on a reciprocal shaker (125 oscills./min, $70 \mathrm{~mm}$ stroke).

- , RL concentrate $2 \%$; ---, control; $O$, total citrates; $\square$, residual 1-tetradecene; $\triangle$, growth (U.O.D. at $660 \mathrm{~nm})$.

* Culture filtrate of Pseudomonas aeruginosa grown on $n$-tetradecane.

cant effect on the production of citrates in the later stage, although no citrates were accumulated in the initial stage. About $30 \%$ of 1 tetradecene consumed in the middle and final stages of the cultivation were converted into citrates in the presence of RL concentrate, and $15 \mathrm{~g} /$ liter of citrates were accumulated on the 6 th day of cultivation, while only $3 \mathrm{~g} /$ liter of citrates were obtained in the absence of RL concentrate.

Based on the above results, the reason why there was no large accumulation of citrates by C. lipolytica at the expense of 1-tetradecene may partly be attributed to the slow metabolic rate of 1-tetradecene. However, the difference in the productivity of citrates between $C$. lipolytica and $C$. tropicalis may not be fully elucidated only by the difference in the rate of metabolism of 1-tetradecene, since $40 \mathrm{~g} /$ liter of citrates were accumulated by $C$. tropicalis at the expense of $40 \mathrm{~g}$ of 1-tetradecene, while 15 $\mathrm{g} /$ liter of citrates were produced from the same amount of 1-tetradecene by $C$. lipolytica even in the presence of surfactants. Therefore, further studies are still required to discover another factor to which the difference in the productivity of citrates could also be attributed.

Acknowledgment. The authors wish to express their sincere thanks to Dr. Hayashi, Mr. Gochou and other members of the Research Laboratory of Hasegawa Koryo Co. Ltd. for their kind advice and help in the GC-MS analyses.

\section{REFERENCES}

1) M. Terasawa and J. Takahashi, Nippon Nôgeikagaku Kaishi, 53, 227 (1979).

2) M. Kusunose, Protein, Nucleic Acid and Enzyme, 2, 50 (1957).

3) Y. Tanaka, Y. Tawara, T. Tabuchi and M. Abe, Nippon Nôgeikagaku Kaishi, 44, 499 (1970).

4) M. J. Klug and A. J. Markovetz, J. Bacteriol., 96, 1115 (1968).

5) M. J. Klug and A. J. Markovetz, Biotechnol. Bioeng., 11, 427 (1969).

6) R. F. Colman, J. Biol. Chem., 243, 2454 (1968).

7) A. Tanaka, H. Maki and S. Fukui, J. Ferment. 
Technol., 45, 1156 (1967).

8) T. Nakahara, K. Hisatsuka, M. Karaki, N. Sano and K. Yamada, Abstracts of Papers, Annual Meeting of Soc. Ferment. Technol. Japan, Osaka, November, 1969 , p. 58.
9) K. Hisatsuka, T. Nakahara and K. Yamada, Agric. Biol. Chem., 35, 686 (1971).

10) S. Itoh, H. Honda and F. Tomita, J. Antibiotics, 23, 855 (1971). 